\title{
RIO DE JANEIRO, A IMAGEM DA DIVISÃO SOCIAL DA CIDADE
}

\author{
NAS EMISSÓES TELEVISIVAS DA FRANÇA
}

\author{
AlbeRTO NAJAR \\ SYLVIE FÉGAR ${ }^{1}$
}

R E S U M O O presente texto tem por objeto de análise as características dos programas da televisão francesa que abordaram a temática das favelas da cidade do Rio de Janeiro/Brasil, em documentos que foram ao ar entre abril de 1964 e maio de 2003. Não se analisarão as imagens propriamente ditas, ou seja, os aspectos particulares pelos quais as cenas elou quadros foram construidos, mas identificar-se-ão características próprias dos documentos audiovisuais que trataram a temática das favelas, em relação aos programas, temas abordados, duração e horário da emissão. Foram utilizadas duas bases de dados da Inathèque de France, a saber: a base do Dépôt Legal e os Archives INA TV (IMAGO). A análise dos resultados sugere que, na TV francesa, o icone predominante da sociedade carioca é o de uma sociedade dicotômica, ricos de um lado, e pobres na favela. Esse icone foi construido através de diversos programas, em que imagens e cenas cotidianas das favelas, sob o gênero de noticiários e magazines, foram transmitidas em boa parte entre 11 h31min e 13h30min, nos canais TF1, FR2 e FR3 (70\% do total das emissöes). Gêneros mais longos, como documentários, com tendência a produzir um quadro de análise e propor uma explicação por vezes mais abrangente, se fizeram presentes, em geral, após 22:30h, nos canais FR2, FR3, Canal + e Arte. Assinala-se na conclusão que a estrutura socioespacial do Rio de Janeiro é mais complexa do que a captada pelo modelo dualista indicado pelos programas analisados. Tal matização socioespacial está ausente nos documentos audiovisuais transmitidos pela TV francesa, e isso os leva a abordar o tema da favela no Rio de Janeiro de uma visão mitico-romântica como a iconizada no filme de Marcel Camus, Orfeu Negro.

P A L A V R A S - C H A V E Rio de Janeiro; imagem da divisão social da cidade; favelas; Inathèque de France; televisão francesa.

\section{APRESENTAÇÃO}

As favelas do Rio de Janeiro são objeto de reflexão desde o início do século XX, em grande quantidade de estudos e abordagens, não apenas no Brasil, conforme cabalmente demonstrado em Valladares (Valladares \& Medeiros, 2003), elas já constam entre as preocupaçôes da agenda de pesquisa sugerida pelo The Comittee on Latin American Anthropology of the National Research Council em 1949 (Tax, Wagley \& Gillin, 1949). Forma de habitar presente na realidade urbana brasileira a partir do final do século XIX, ocupa lugar de destaque no imaginário francês como exemplo de realidade social e urbana deteriorada, o lugar da pobreza, o território por excelência dos pobres, o que acaba criando uma espécie de determinismo metodológico, fazendo que a favela seja abordada como se fora uma unidade, seja analítica, seja política e, no caso em estudo, conforme será apresentado, como uma unidade jornalístico-documental. Para uma abordagem sistemática e uma 
discussão crítica a respeito dessas questões, consultar Valladares (2001; 2002a; 2002b). Dessa maneira, a favela passa a ser o ícone da própria divisão social da cidade, e o Rio de Janeiro, o ícone de uma suposta polarização urbano-metropolitana da cidade brasileira, de onde está ausente toda e qualquer mediação, em termos de categorias e classes sociais.

Reforçam-se, assim, a um só tempo, o imaginário antigo dos trópicos como o lugar da exuberância, quer seja da natureza quer seja da miséria - a velha imagem dos trópicos "ensolarados e miseráveis" (Vilan, 1993) -, e o paradigma europeu de cidade, o lugar privilegiado, do modelo de ordem (Santos, 2001).

Apesar de o espaço urbano no Rio de Janeiro e brasileiro ter sofrido importantes transformações, especialmente no que se refere à sua estrutura social, essas mudanças não tiveram visibilidade na mídia televisiva francesa, cuja hipótese implícita de abordagem centra-se na distribuição concêntrica, contínua e contígua entre espaços de características sociais similares a partir do núcleo metropolitano. Existem, entretanto, diversos trabalhos e análises, apoiados em farto material empírico, que sugerem a presença de um tecido social complexo, tanto no Rio de Janeiro quanto em outras metrópoles brasileiras, onde espaços de características similares se encontram em locais distintos e não-contíguos, contribuindo com outros elementos para o estudo da localização das atividades e grupos no espaço (Navez-Bouchanine, 2002; Valladares, 2002a). Por que essa permanência? Essa é uma das questôes que o presente artigo pretende discutir.

\section{MATERIAL UTILIZADO E ASPECTOS METODOLÓGICOS}

Essa é uma primeira abordagem de farto material empírico acerca dos programas televisivos que veicularam, na França, imagens das favelas cariocas. A quantidade e a qualidade do material aos quais os autores tiveram acesso só permitem uma abordagem por aproximaçôes sucessivas, cujo primeiro ensaio ora oferecemos.

No sentido de permitir melhor apreciação do material, dos dados utilizados e das limitações do presente artigo, pareceu necessário apresentar, de forma breve, suas principais características. A Inathèque de France, criada em janeiro de 1993 (Inathèque de France - INA, 2003), constitui um dos departamentos do denominado Patrimoine de l'Institut National

20 Dépôt Legal foi criado por François I em 1537, modificado em 1943 e 1992. de l'Audiovisuel, estando sob sua responsabilidade a gestão do Dépôt Légal ${ }^{2}$ (Depósito Legal) do rádio e da televisão (France. Assemblée Nationale, 1992). O Dépôt Légal cumpre dupla missão: assegurar a conservação de um suporte audiovisual com qualidade idêntica àquela de sua produção, assim como dar acesso à consulta com fins de pesquisa (Dreyer 2003).

A investigação cujos resultados são ora apresentados foi conduzida em duas bases de dados, cuja história de constituição, montagem e aquisição de dados explica, pelo menos em parte, as disparidades de tratamento dos diversos documentos que as constituem (Inathèque de France - INA, 2003):

Dépôt Legal TV (Depósito Legal) (DLTV): é onde se encontra recenseada, a partir de 1995, toda a difusão de programas de rádio e da televisão na França, ou seja, tudo o que foi transmitido, objeto ou não do Dépôt Légal. Todos os documentos audiovisuais dessa base de dados são submetidos à identificação no conjunto da grade de programação (títulos, elementos de difusão, natureza da produção, gênero etc.). Da mesma forma são registrados os chamados "interprogramas" (publicidade e anúncios das emissoras). A catalogação e o tratamento documental são feitos apenas para os programas que constituem o 
Dépôt Légal propriamente dito (ver Tabela 1), que, por sua vez, são objeto de tratamento documental diferenciado, de acordo com o tipo de emissão. Os canais submetidos ao Dépôt Légal, para as emissões que abrangem todo o território nacional francês, são os seguintes: TF1, FR2, FR3, Canal +, La Cinquième (FR5), Arte e M6. Os princípios de coleta observados são dois, a saber, programas de origem francesa e os de primeira transmissão (a partir de 1/1/1995).

Tabela 1 - Critérios de classificação e coleta dos programas pela Inathèque

\begin{tabular}{lcc}
\hline Emissão & Depósito exaustivo & Depósito seletivo \\
\hline Magazines & $\mathrm{X}$ & \\
Emissões de informação & $\mathrm{X}$ & \\
Ficção TV* & $\mathrm{X}$ & \\
Desenhos animados* & $\mathrm{X}$ & \\
Espetáculos* & $\mathrm{X}$ & \\
Documentários* & $\mathrm{X}$ & \\
Vídeos musicais* & $\mathrm{X}$ & \\
Curtas-metragens* & $\mathrm{X}$ & \\
Variedades & $\mathrm{X}$ & $1 /$ jornal/canal/dia \\
Mensagens publicitárias & $\mathrm{X}$ & $4 /$ título/ano/canal \\
Jornais televisados & & $4 / \mathrm{modalidade/canal/ano}$ \\
Jogos & & $4 /$ título/canal/ano \\
Retransmissões esportivas & & Amostras \\
Outras emissōes ou elementos de emissões superiores a 13' & & $7 /$ canal/ano \\
Outras emissões ou elementos de emissões inferiores a 13' (anúncios...) & & \\
Jornadas-testemunha & & \\
\hline
\end{tabular}

* Obras audiovisuais (oeuvres audiovisuelles).

Fonte: INA, 2003.

Archives INA TV (Arquivos INA) (IMAGO): onde são recenseados os arquivos cuja finalidade é o uso profissional. IMAGO é uma base de dados documental, criada com a finalidade de responder às demandas profissionais em matéria de arquivos televisivos. Trata-se, portanto, de uma ferramenta documental dirigida especialmente aos jornalistas, produtores e realizadores, adaptada às necessidades de pesquisa de imagens de ilustração ou demanda de redifusão integral. Possui ainda outra característica importante, qual seja, a de ser alimentada, cotidianamente, por informações dos programas produzidos pelos canais públicos e pela TF1, privatizada em 1995.

As primeiras pesquisas exploratórias nas bases de dados indicaram que os documentos que interessariam para análise poderiam ser encontrados a partir dos seguintes descritores: favelas ou bidonvilles ou ghetto e Rio de Janeiro ou Brésil. Esses verbetes foram utilizados para uma indagação exaustiva nas bases de dados, com todas as grafias possíveis. A distribuição dessa primeira sondagem é apresentada na Tabela 2, da qual se deduz que, dentre todo o material televisado nos canais abertos da França e classificado pelos catalogadores como programas que tratam de bidonvilles, favelas e ghettos, 13,6\% (270 ocorrências sobre 1.990) continham imagens de favelas do Brasil, entre os quais, 43\% (116 ocorrências sobre 270) transmitiram imagens de favelas do Rio de Janeiro, que, por sua vez, representam 5,8\% do total (116 ocorrências sobre 1.990). Em termos 
quantitativos, as pesquisas levaram, conforme já assinalado, à recuperação de 116 documentos audiovisuais, que tiveram seus diversos campos examinados, o que permitiu eliminar algumas redundâncias.

Deve-se destacar ainda que, para três jornais televisivos - Le Brésil (20/1/1976); Adresse Bidonville (2/11/1983) e Massacre Favellas Brésil (31/8/1993) -, não foi possível recuperar a duração, tendo-lhes sido atribuída a duração típica de 1'30”. De forma semelhante, foi solucionado o problema da ausência de registro da duração no documento Plateau Camara (6/11/1983), atribuindo-se, nesse caso, a duração da emissão, (20'), à duração da entrevista. Deve ficar claro que essas decisões são fontes de erros potenciais (consultar o Quadro 1).

Tabela 2 - Distribuição de documentos audiovisuais segundo palavras-chave e segundo agregação geográfica

\begin{tabular}{llll}
\hline & \multicolumn{3}{c}{ Palavras-chave: bidonville, favela e ghetto (todas as ortografias) } \\
\hline & Total & Brasil & Rio de Janeiro \\
\hline DLTV $^{*}$ & 1.205 & 144 & 54 \\
IMAGO** $^{*}{ }^{*}$ & 785 & 126 & 62 \\
Total & 1.990 & 270 & 116 \\
\hline
\end{tabular}

* Pesquisa pelo campo 'Index général' (índice geral).

** Pesquisa pelo campo 'Index mots clés' (índice de palavras-chave).

Fonte: INA.

Deve-se ponderar esses resultados, lembrando-se de que a cidade do Rio de Janeiro foi abordada sob diversas formas, e de diversas óticas, durante o período em estudo, em 714 emissões televisivas, das quais 16,25\% (116) trataram do tema favelas.

Dada a diferença de sistemática de codificação das duas bases de dados, o material selecionado foi objeto de diversas aproximações, tendo sido feita uma caracterização do conjunto para construir e discutir um perfil abrangente. $\mathrm{O}$ material foi agrupado segundo faixas de horários de disseminação e analisado nesse grupamento. Neste caso, adotou-se a seguinte partilha: entre $11 \mathrm{~h} 31$ e 13h30, que foi chamado de "déjeuner" ou "almoço"; entre $13 \mathrm{~h} 31 \mathrm{e}$ 17h29, que recebeu a designação de "après-midi"; entre 17h30 e 19h30 ("access prime time" ou "acesso ao horário nobre"); entre 19h31 e 22h30 ("prime time" ou "horário nobre"); e após $22 \mathrm{~h} 31$ até $11 \mathrm{~h} 30$ ("pós-prime time"). Uma análise de correspondência foi feita utilizando-se quatro variáveis, a saber: canal; faixa de horário; duração de transmissão; e assunto.

Alguns documentos foram visualizados (mais exatamente, 16 documentos) para permitir aproximação mais precisa e comparação com as opções de abordagem. Foi o caso, por exemplo, de todos os documentos que assinalaram, do ponto de vista dos autores, uma periodização. Para discussão mais aprofundada a respeito das opçóes de análise adotadas nesse artigo, ver Sfez (1993); Leboeuf \& Mégy (1998); Souchon (1998).

Esses documentos, distribuídos ao longo de quarenta anos, entre 3 de abril de 1964 e 9 de maio de 2003, passaram a constituir o corpus da análise, baseado no qual foram feitas pesquisas mais refinadas - consultar o Quadro 1 (em anexo).

$\mathrm{O}$ arquivo de documentos foi examinado sistematicamente, documento a documento, a partir dos principais campos da base de dados (titulo, duração, temática, gênero, descritores e resumos), em seguida foram definidos assuntos relacionados às diversas emissóes, nos quais cada transmissão foi classificada. $\mathrm{O}$ resultado dessa operação é apresentado nas Tabelas 3 e 4, nas quais, a cada tipologia, corresponde um único tema. Nunca é demais 
assinalar a subjetividade que está envolvida na criação de um esquema classificatório. Refere-se, no caso ora apresentado, à classificação da tipologia do programa e aos temas abordados. Enquanto a primeira encontra-se já definida nas bases de dados utilizadas, cuja sistematização foi realizada pelos documentaristas do INA, a segunda é escolha exclusiva dos autores. Para uma abordagem precisa dessa discussão, remete-se o leitor para Bourdieu (1968; 1979), Boltanski (1970) e Chenu (1997).

Tabela 3 - Distribuição da tipologia e dos temas abordados, 1964-2003

\begin{tabular}{|c|c|c|c|c|c|c|c|}
\hline Tema & Magazine & $\begin{array}{l}\text { Repor- } \\
\text { tagem }\end{array}$ & Jornal & $\begin{array}{c}\text { Docu- } \\
\text { mentário }\end{array}$ & $\begin{array}{l}\text { Teste- } \\
\text { munho }\end{array}$ & Ficção & $\begin{array}{c}\text { Total } \\
\text { global }\end{array}$ \\
\hline Alternativas & 1 & & 2 & 3 & & & 6 \\
\hline Carnaval & & 2 & 4 & & & & 6 \\
\hline Cinema & & 3 & 3 & 1 & & 3 & 10 \\
\hline Clichê & & & 4 & & & & 4 \\
\hline Comparação internacional & & 3 & & & 1 & & 4 \\
\hline Condições de vida & 3 & 1 & 5 & & 1 & & 10 \\
\hline Cooperação França/Brasil & & & 6 & & & & 6 \\
\hline Compreensão & 2 & 2 & 3 & 10 & 1 & & 18 \\
\hline Crianças/jovens & 2 & 3 & 4 & 3 & 1 & 1 & 14 \\
\hline Futebol & & 1 & 1 & 1 & & & 3 \\
\hline Fórum social & & 1 & 4 & & & & 5 \\
\hline Hiphop & & & 3 & 1 & & & 4 \\
\hline Violência & & 1 & 16 & 1 & & & 18 \\
\hline Total global & 8 & 17 & 55 & 20 & 4 & 4 & 108 \\
\hline
\end{tabular}

Tabela 4 - Repartição dos documentos audiovisuais segundo a tipologia e canais, 1964-2003

\begin{tabular}{lccccccc}
\hline Canal & Magazine & $\begin{array}{c}\text { Repor- } \\
\text { tagem }\end{array}$ & Jornal & $\begin{array}{c}\text { Docu- } \\
\text { mentário }\end{array}$ & $\begin{array}{c}\text { Teste- } \\
\text { munho }\end{array}$ & $\begin{array}{c}\text { Ficçáo } \\
\text { Total } \\
\text { global }\end{array}$ \\
\hline TF1 & 3 & 2 & 25 & 3 & 1 & & 34 \\
FR2 & 3 & 5 & 15 & 6 & 2 & 1 & 32 \\
FR3 & 2 & 3 & 11 & 3 & & 1 & 20 \\
Canal + & & 1 & & 1 & & 2 & 4 \\
M6 & & 2 & 2 & 1 & 1 & & 6 \\
Arte & & 2 & 2 & 5 & & & 9 \\
FR5 & & 2 & & 1 & & & 3 \\
Total global & 8 & 17 & 55 & 20 & 4 & 4 & 108 \\
\hline
\end{tabular}

Deve-se registrar ainda a descrição das tipologias das transmissões. Foram encontradas cinco tipologias, apresentadas em seguida, tal como definidas no âmbito da televisão francesa:

Documentário (Documentaire): documento cuja principal característica é o de ser feito por um realizador e não por um jornalista, como no caso da reportagem. O documentário é geralmente informativo, abordando todos os domínios. O documentário guarda um distanciamento maior do que a reportagem, no que se refere ao tema abordado;

Jornal (Journal): emissão cotidiana de atualidades, composta de reportagens, normalmente dedicadas ao conjunto de informações políticas, econômicas, sociais, artísticas e culturais. Pode ser também um jornal especializado do ponto de vista temático (economia e esporte, em particular); 
3 A tipologia magazine refere-se a uma emissão geralmente temática (cultural, esportiva etc.) de caráter atual e conteúdo informativo.
Magazine (Magazine): ${ }^{3}$ emissão estruturada e com periodicidade regular em torno de diversos temas. O conteúdo geralmente é informativo e ligado à atualidade em todos os seus domínios, política, esportes, economia, sociedade, vida cotidiana, ciência, arte etc.;

Reportagem (Reportage): assinada por um jornalista, aborda basicamente temas políticos, econômicos ou sociais (vida cotidiana, fatos e problemas sociais), em particular nos formatos curtos (entre 45 segundos e dois minutos), sendo freqüentemente difundida no contexto do gênero jornal ou magazine;

Testemunho (Témoignage): entrevista, de uma ou várias pessoas, sobre um acontecimento em que ela (eles) teve (tiveram) participação direta, vendo, ouvindo ou vivendo.

\section{ANÁLISE dOS RESULTADOS}

Imagens das favelas do Rio de Janeiro sempre foram difundidas pela televisão francesa de uma perspectiva jornalístico-documental que associava carnaval, más condiçóes de vida e violência. A favela e seu entorno foram sistematicamente apresentados como o resultado direto e exclusivo de uma sociedade dual e polarizada, sem categorias sociais mediadoras. Mais da metade das emissões (sessenta documentos) se concentraram em quatro temas fortemente interligados, quais sejam, a violência urbana (violence), as tentativas de explicar o porquê das favelas (encadrement), a situação das crianças e dos jovens, moradores ou saídos dessas favelas (enfants/jeunes), e as condiçôes de vida no seu interior ou entorno imediato (conditions de vie).

Observando-se os resultados da análise fatorial (análise de correspondência) - ver Gráficos 1 e 2 -, constata-se que o primeiro plano fatorial é definido pela oposição entre notícias e transmissões curtas por um lado (violência e imagens clichês transmitidas em emissões de curta duração) e tentativas de compreensão (encadrement, com duração bem mais longas) de outro. Esboça-se uma oposição formada, de um lado, por TF1 e, por outro, pelo grupo integrado por FR2, FR3, Canal+ e Arte, assinalando claramente uma clivagem, tanto na maneira de abordar como nos temas tratados. Nota-se, também, uma oposição entre as faixas de horário. A faixa chamada de déjeuner (11h31 e 13h30), por um lado, e a faixa chamada de pós-prime time (após 22h31), de outro, assinalando a pouca importância do tema das favelas, o que é reforçado quando se observa o tempo das respectivas transmissões: no primeiro caso com duração em torno de dois minutos e no segundo caso chegando a ultrapassar uma hora de duração.

Levando em consideração os temas dos programas, constata-se que predominam, no primeiro grupo, notícias a respeito da violência e imagens que reforçam clichês lugarescomuns e idéias herdadas, seja a dos trópicos violentos seja a dos trópicos como o lugar de liberação dos costumes e exuberância da natureza (clichê), enquanto no segundo grupo prevalecem as abordagens mais longas, classificadas como encadrement, que representam uma tentativa de compreensão.

O segundo plano fatorial opõe temas culturais (cinema e turismo), transmitidos pelo canal FR5, e questões admitidas como estando interrelacionadas (violence, favelas e hiphop), difundidas, em particular, pelo canal M6. A maior parte das difusões ocorreu no chamado aprés-midi (período da tarde) que funciona como um "horário tampão", antes do prime-time. Do ponto de vista da duração, as menores do que 1'19", estão associadas às emissões a respeito da violência, onde predomina a difusão de imagens impactantes, enquanto nos outros casos, a duração passa a se distribuir entre 1'58' e 10'16". A polari- 
A $\quad$ L

Gráfico 1 - Planos fatoriais 1 e 2.

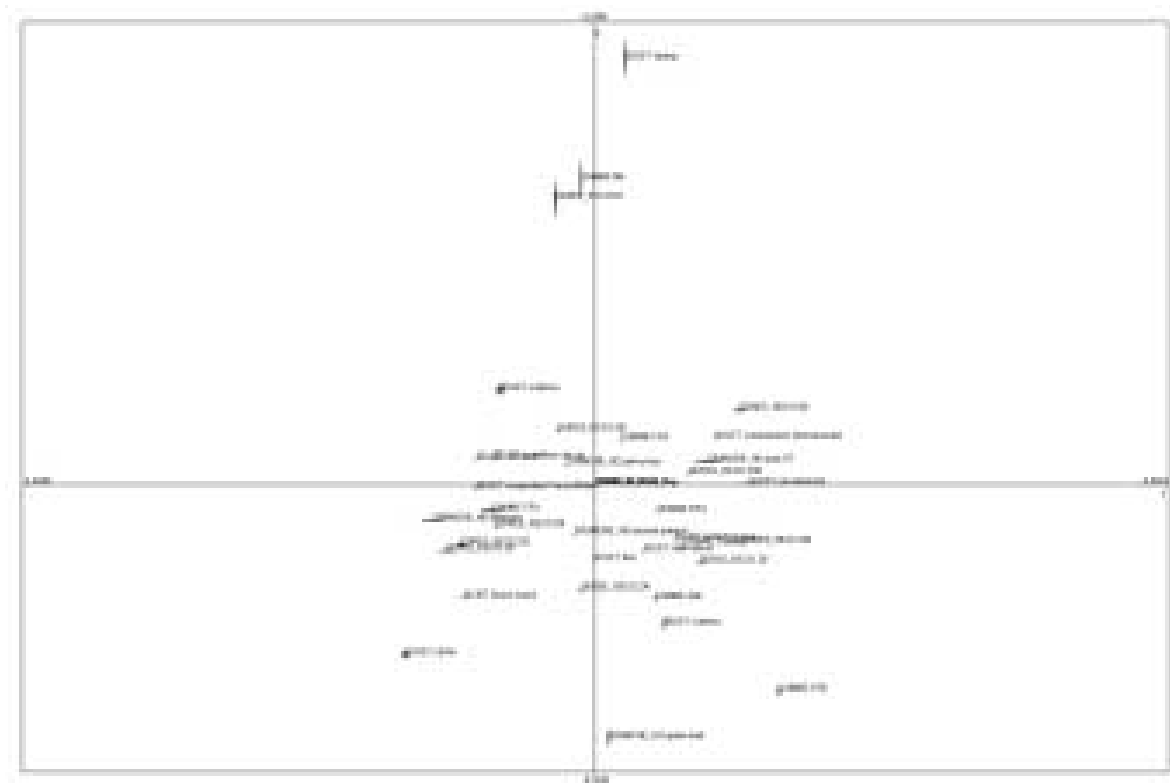

Gráfico 2 - Planos fatoriais 1 e 3.

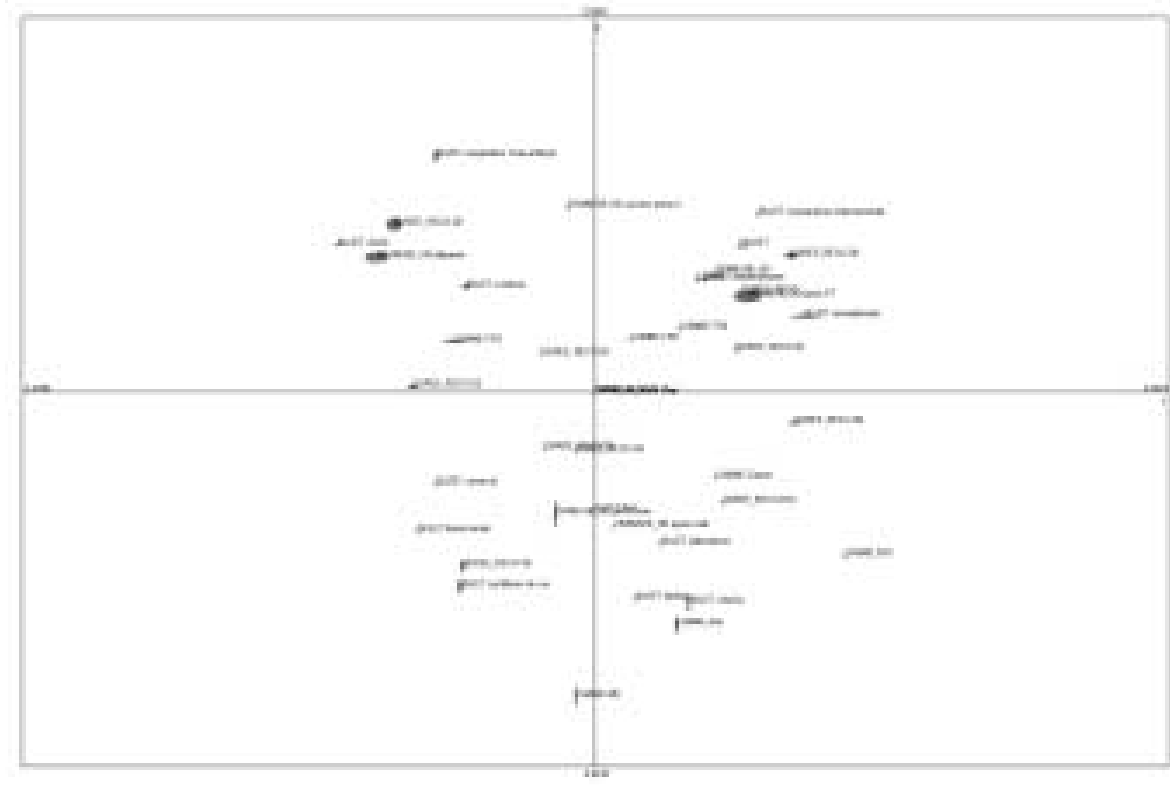

zação (maiores contribuições ao plano fatorial e coordenadas maiores) agrupa, de um lado, o tema do hiphop, as imagens cliché, o canal M6, sugerindo um padrão de transmissão em forma de clipes; e de outro lado, emissões que tratam do cinema e da violência, tendo como canais difusores o FR5 e o canal Arte, que dividem o mesmo canal de transmissão ao longo de uma jornada diária. Embora a faixa de horário predominante seja o après-midi, que segundo a definição feita no âmbito desse estudo se distribui entre $13 \mathrm{~h} 31 \mathrm{~min}$ e $17 \mathrm{~h} 29 \mathrm{~min}$, a duração situa-se entre o quarto e o sétimo decis, ou seja, entre 2'42" e 25'55'.

O terceiro fator também indica uma clivagem entre notícias e esforço de compreensão, como no caso do primeiro fator, mas dessa vez tendo como a variável de maior contribuição a faixa de horário nobre, a chamada prime-time, na qual as difusões são notícias ou reportagens com grande potencial de impacto, função do horário de difusão. Esse 
terceiro fator agrupa, de um lado, os temas condições de vida e cinema; os canais M6 e Arte; como duração, a do sexto decil (ponto de corte em 10'16”) e como faixa de horário o prime-time; e, de outro lado, encontram-se os temas da cooperação França/Brasil, a violência; o segundo decil e o nono decil e as faixas de horário: pós-prime time (após o horário nobre), déjeuner e access prime time (acesso ao horário nobre), nesta ordem de contribuição. Note-se que não há contribuição relevante de um canal, o que pode estar indicando que os citados temas se distribuem sobre toda a grade de canais.

Documentos audiovisuais divulgados em meios de comunicação televisados são fortemente influenciados pela manipulação do material original e pelos métodos de montagem. Esses dois aspectos, por sua vez, estão relacionados ao processo de trabalho, induzindo as diversas possibilidades de construção e de apresentação da notícia (Siracusa, 1998). Diferentemente da idéia predominante de que as reportagens televisionadas dependem sobretudo das imagens, é o texto escrito que guia a montagem da informação televisada (Siracusa, 2000, p.92). A lógica que predomina é a de uma sobreposição, normalmente conduzida por um texto previamente gravado. É nesse processo que vai se definir a permanência de um tema, a duração dos assuntos, assim como a ordem de divulgação. Ou seja, ainda que as informações sejam difundidas a partir de documentos audiovisuais, a divulgação repousa sobre o tratamento que receberam, na maior parte das vezes separadamente, as imagens e o texto. Para uma discussão sistemática a respeito dessa questão, ver Marchetti (1997) e Mills-Affif (2002).

As reportagens divulgadas nos jornais televisados, por exemplo, são, portanto, uma montagem coletiva, e as informações que elas veiculam são o resultado de uma interpretação, de um processo de trabalho, de uma seleção, de um ponto de vista e das condiçóes no momento da filmagem, apenas para citar alguns fatores de enviesamento. No caso da presente análise, entre os 108 documentos audiovisuais, 55 estão classificados como jornais televisados, totalizando $1 \mathrm{~h} 51$ de transmissão entre 1964 e 2003 (consultar as Tabelas 5 e 6). Sem dúvida pouco tempo, mas deve-se avaliá-lo considerando-se que mais da metade dos documentos (trinta documentos) foram difundidos entre $17 \mathrm{~h} 30$ e $22 \mathrm{~h} 30$, ou seja, em faixas de horário de grande impacto e em assuntos bem focados e repetitivos, que terminam por se reforçarem mutuamente (Tabelas 7 e 8). Até mesmo os pontos extremos da distribuição da duração dos jornais reforçam a visão consolidada sobre a divisão social da cidade do Rio de Janeiro: a primeira de 4'50', que abordou em março de 1992 o carnaval, e a segunda, com uma duração excepcional de 7'59”, de outubro de 1989, cujo tema foi "Favelas à Rio", que abordou longamente o tema da violência. Ambas, apesar da duração inusitada, já assinalam uma característica: a de abordar, alternadamente ao longo de um ano, o carnaval e a violência, associando-as como uma espécie de catarse tropical.

Tabela 5 - Repartição da duração das emissões, em minutos, segundo a tipologia, por canal, 1964-2003

\begin{tabular}{lccccccc}
\hline Canal & Magazine & $\begin{array}{c}\text { Repor- } \\
\text { tagem }\end{array}$ & Jornal & $\begin{array}{c}\text { Docu- } \\
\text { mentário }\end{array}$ & $\begin{array}{c}\text { Teste- } \\
\text { munho }\end{array}$ & Ficção & $\begin{array}{c}\text { Total } \\
\text { global }\end{array}$ \\
\hline TF1 & $0: 56: 25$ & $1: 09: 00$ & $0: 58: 34$ & $2: 12: 35$ & $0: 20: 00$ & & $5: 36: 34$ \\
FR2 & $0: 53: 09$ & $2: 28: 41$ & $0: 27: 34$ & $4: 45: 48$ & $1: 29: 30$ & $1: 29: 19$ & $11: 34: 01$ \\
FR3 & $1: 00: 21$ & $1: 58: 02$ & $0: 21: 55$ & $2: 44: 00$ & & $1: 24: 40$ & $7: 28: 58$ \\
Canal+ & & $0: 06: 25$ & & $0: 49: 04$ & & $0: 40: 57$ & $1: 36: 26$ \\
M6 & & $1: 49: 52$ & $0: 00: 51$ & $0: 54: 07$ & $0: 02: 31$ & & $2: 47: 21$ \\
Arte & & $0: 28: 28$ & $0: 03: 03$ & $4: 11: 21$ & & & $4: 42: 52$ \\
FR5 & & $0: 31: 43$ & & $0: 13: 34$ & & & $0: 45: 17$ \\
Total global & $2: 49: 55$ & $8: 32: 11$ & $1: 51: 57$ & $15: 50: 29$ & $1: 52: 01$ & $3: 34: 56$ & $34: 31: 29$ \\
\hline
\end{tabular}


Tabela 6 - Repartição da duração dos programas, em minutos, segundo os temas abordados nos jornais, por canal, 1964-2003

\begin{tabular}{lcccccc}
\hline Tema & Arte & FR1 & FR2 & FR3 & M6 & Total global \\
\hline Condições de vida & $0: 01: 23$ & $0: 04: 33$ & $0: 02: 19$ & & & $0: 08: 15$ \\
Alternativas & & $0: 02: 28$ & $0: 04: 45$ & & & $0: 07: 13$ \\
Carnaval & & $0: 10: 26$ & $0: 01: 34$ & & & $0: 12: 00$ \\
Cinema & & $0: 01: 31$ & & $0: 04: 23$ & & $0: 05: 54$ \\
Clichê & & $0: 07: 15$ & & & & $0: 07: 15$ \\
Condições de vida & $0: 02: 04$ & & & & $0: 02: 04$ \\
Cooperação França/Brasil & & $0: 06: 13$ & $0: 02: 20$ & $0: 02: 05$ & & $0: 10: 38$ \\
Compreensão & & & $0: 03: 02$ & $0: 04: 41$ & & $0: 07: 43$ \\
Crianças/jovens & & $0: 01: 30$ & & $0: 04: 10$ & & $0: 05: 40$ \\
Futebol & & & $0: 01: 55$ & & $0: 01: 55$ \\
Fórum social & $0: 01: 40$ & $0: 03: 14$ & & $0: 02: 15$ & & $0: 07: 09$ \\
Hiphop & & & $0: 01: 05$ & & $0: 00: 51$ & $0: 01: 56$ \\
Violência & & $0: 19: 20$ & $0: 12: 29$ & $0: 02: 26$ & & $0: 34: 15$ \\
Total global & $0: 03: 03$ & $0: 58: 34$ & $0: 27: 34$ & $0: 21: 55$ & $0: 00: 51$ & $1: 51: 57$ \\
\hline
\end{tabular}

Tabela 7 - Duração total dos temas por faixa de horário, 1964-2003

\begin{tabular}{lcccccc}
\hline Tema & Post-PT & Déjeuner & $\begin{array}{c}\text { Après- } \\
\text { midi }\end{array}$ & $\begin{array}{c}\text { Access prime } \\
\text { time }\end{array}$ & $\begin{array}{c}\text { Prime } \\
\text { time }\end{array}$ & $\begin{array}{c}\text { Total } \\
\text { global }\end{array}$ \\
\hline Alternativas & $0: 13: 34$ & & $0: 02: 15$ & & $1: 30: 30$ & $1: 46: 19$ \\
Carnaval & $1: 07: 29$ & $0: 08: 41$ & & & $1: 45: 28$ & $3: 01: 38$ \\
Cinema & $0: 54: 54$ & & $0: 04: 56$ & $0: 19: 28$ & $3: 08: 53$ & $4: 28: 11$ \\
Clichê & $0: 01: 20$ & $0: 01: 30$ & $0: 02: 05$ & & $0: 02: 20$ & $0: 07: 15$ \\
Comparação internacional & $2: 24: 29$ & $0: 38: 00$ & & & $0: 48: 05$ & $3: 50: 34$ \\
Condições de vida & $0: 32: 06$ & $0: 02: 19$ & & & $0: 29: 19$ & $1: 03: 44$ \\
Cooperação França/Brasil & $0: 03: 09$ & $0: 02: 44$ & & $0: 02: 36$ & $0: 02: 09$ & $0: 10: 38$ \\
Compreensão & $5: 39: 07$ & & & $0: 20: 00$ & $3: 49: 36$ & $9: 48: 43$ \\
Crianças/jovens & $4: 29: 56$ & $0: 02: 00$ & $0: 12: 26$ & $0: 03: 00$ & $1: 17: 02$ & $6: 04: 24$ \\
Futebol & & $0: 01: 55$ & & & $1: 21: 26$ & $1: 23: 21$ \\
Fórum social & & $0: 06: 25$ & & & $0: 07: 09$ & $0: 13: 34$ \\
Hiphop & $0: 49: 04$ & & & & $0: 01: 56$ & $0: 51: 00$ \\
Violência & $0: 58: 09$ & $0: 13: 34$ & & $0: 00: 56$ & $0: 29: 29$ & $1: 42: 08$ \\
Total global & $17: 13: 17$ & $1: 17: 08$ & $0: 21: 42$ & $0: 46: 00$ & $14: 53: 22$ & $34: 31: 29$ \\
\hline & & & & & &
\end{tabular}

Tabela 8 - Duração total dos temas abordados nos jornais por faixa de horário, 1964-2003

\begin{tabular}{lcccccc}
\hline Tema & Post-PT & Déjeuner & $\begin{array}{c}\text { Après- } \\
\text { midi }\end{array}$ & $\begin{array}{c}\text { Access prime } \\
\text { time }\end{array}$ & $\begin{array}{c}\text { Prime } \\
\text { time }\end{array}$ & $\begin{array}{c}\text { Total } \\
\text { global }\end{array}$ \\
\hline Alternativas & & & $0: 02: 15$ & & $0: 04: 58$ & $0: 07: 13$ \\
Carnaval & & $0: 08: 41$ & & & $0: 03: 19$ & $0: 12: 00$ \\
Cinema & & & & & $0: 05: 54$ & $0: 05: 54$ \\
Clichê & $0: 01: 20$ & $0: 01: 30$ & $0: 02: 05$ & & $0: 02: 20$ & $0: 07: 15$ \\
Condições de vida & $0: 02: 06$ & $0: 02: 19$ & & & $0: 05: 54$ & $0: 10: 19$ \\
Cooperação França/Brasil & $0: 03: 09$ & $0: 02: 44$ & & $0: 02: 36$ & $0: 02: 09$ & $0: 10: 38$ \\
Compreensão & $0: 07: 43$ & & & & & $0: 07: 43$ \\
Crianças/jovens & & $0: 02: 00$ & & $0: 01: 30$ & $0: 02: 10$ & $0: 05: 40$ \\
Futebol & & $0: 01: 55$ & & & & $0: 01: 55$ \\
Fórum social & & & & & $0: 07: 09$ & $0: 07: 09$ \\
Hiphop & & & & & $0: 01: 56$ & $0: 01: 56$ \\
Violência & $0: 02: 47$ & $0: 13: 34$ & & $0: 00: 56$ & $0: 16: 58$ & $0: 34: 15$ \\
Total global & $0: 17: 05$ & $0: 32: 43$ & $0: 04: 20$ & $0: 05: 02$ & $0: 52: 47$ & $1: 51: 57$ \\
\hline
\end{tabular}

No que se refere à variação temporal no período estudado, tanto da duração da transmissão quanto da quantidade de documentos transmitidos por décadas (Tabela 9 e 
Figuras 1 e 2), pode-se identificar a existência de algumas inflexōes. A primeira, situada entre 1964 e 1978, onde o tema da favela é associado exclusivamente ao carnaval. Representativa desse período é a emissão dirigida por Larriaga - Les coulisses d’un carnaval [Os bastidores de um carnaval] -, (Larriaga 1968), onde as favelas são classificadas como: "bidonvilles acrochés aux colines" ["moradias provisórias penduradas em morros"] e o samba como "une étrange répétition" ["uma cadência bizarra"]. Uma sequiência de imagens define a favela e parece fixar sua própria imagem, com a seqüência narrativa conduzida pelo depoimento de uma missionária, irmã Anne. Inicialmente o locutor anuncia: "..la misère a ses pudeurs, ici comme ailleurs. La favela c'est ça!!!” ["a miséria tem seus pudores, aqui como alhures. A favela é isso aí!!!”, dando a "dica” para uma seqüência de imagens mudas, na seguinte ordem: 1 criança escalando uma árvore; 2 câmera rápida dando uma visão geral de uma rua sem calçamento, parando em um animal que caminha a esmo; 3 homem negro catando lixo; 4 galinha e pintos ciscando a terra imunda; 5 duas crianças negras brincando com um latinha, num quintal estreito em terra úmida e imunda; 6 uma mulher manipulando uma corrente para tirar água de um poço; 7 a seqüência termina mostrando os acessos precários para subir o morro. Nesse ponto o interlocutor intervem de novo como que em resumo: "on y descend le matin pour travailler, on y remonte le soir plus près du ciel" ["desce-se para o trabalho pela manhã, sobe-se à noite mais para perto do céu”]. Depois disso há um corte e inicia-se o contraste com a cidade, que é apresentada como o lugar da opulência.

Tabela 9 - Repartição da duração dos programas, em minutos, segundo a tipologia, por décadas, 1964-2003

\begin{tabular}{|c|c|c|c|c|c|c|c|c|c|c|c|c|c|c|}
\hline \multirow[t]{2}{*}{ Ano } & \multirow{2}{*}{\multicolumn{2}{|c|}{$\begin{array}{c}\text { Documen- } \\
\text { tário } \\
\text { (n. e \%) }\end{array}$}} & \multirow{2}{*}{\multicolumn{2}{|c|}{$\begin{array}{l}\text { Ficção } \\
\text { (n. e \%) }\end{array}$}} & \multirow{2}{*}{\multicolumn{2}{|c|}{$\begin{array}{l}\text { Jornal } \\
\text { (n. e \%) }\end{array}$}} & \multirow{2}{*}{\multicolumn{2}{|c|}{$\begin{array}{c}\text { Magazine } \\
\text { (n. e \%) }\end{array}$}} & \multirow{2}{*}{\multicolumn{2}{|c|}{$\begin{array}{c}\text { Reportagem } \\
\text { (n. e \%) }\end{array}$}} & \multirow{2}{*}{\multicolumn{2}{|c|}{$\begin{array}{l}\text { Testemunho } \\
\text { (n. e \%) }\end{array}$}} & \multirow{2}{*}{\multicolumn{2}{|c|}{$\begin{array}{l}\text { Total } \\
\text { (n. e \%) }\end{array}$}} \\
\hline & & & & & & & & & & & & & & \\
\hline$\overline{1960}$ & 0 & 0 & 0 & 0 & 0 & 0 & 26 & 100 & 0 & 0 & 0 & 0 & 26 & 100 \\
\hline 1970 & 45 & 76 & 0 & 0 & 1 & 2 & 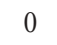 & 0 & 13 & 2 & 0 & 0 & 59 & 100 \\
\hline 1980 & 187 & 46 & 0 & 0 & 50 & 12 & 124 & 30 & 48 & 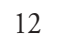 & 0 & 0 & 409 & 100 \\
\hline 1990 & 705 & 48 & 215 & 15 & 38 & 3 & 20 & 1 & 392 & 2 & 90 & 6 & 1459 & 100 \\
\hline 2000 & 14 & 15 & 0 & 0 & 16 & 17 & 0 & 0 & 59 & 6 & 3 & 3 & 91 & 100 \\
\hline Total & 950 & 46 & 215 & 11 & 105 & 5 & 170 & 8 & 512 & 25 & 92 & 4 & 2045 & 100 \\
\hline
\end{tabular}

Figura 1 - Distribuiçãao da duração de transmissão, em minutos, segundo a tipologia, por décadas, 1964-2003.

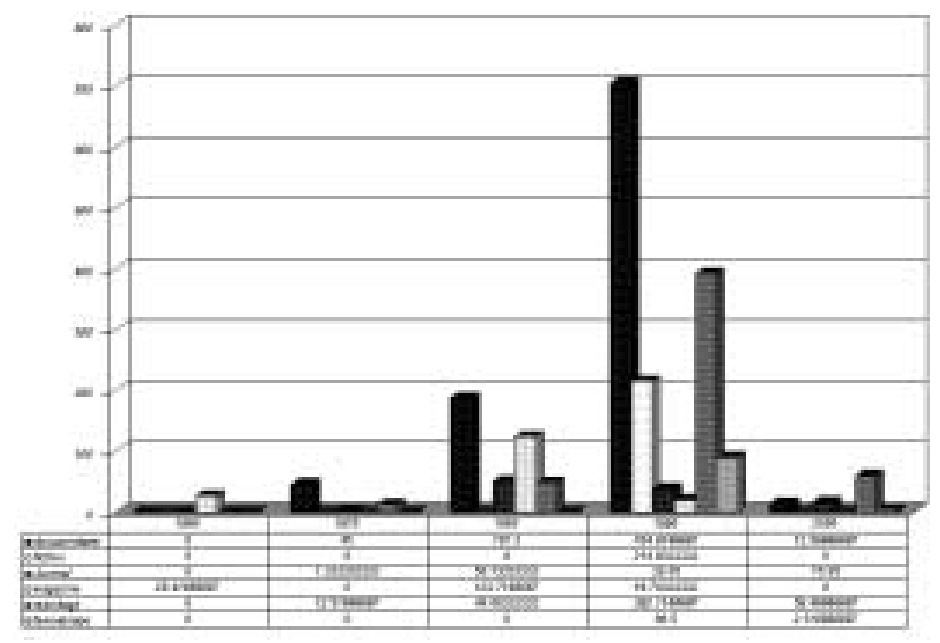


Figura 2 - Variação anual da duração das transmissões, 1964-2003.

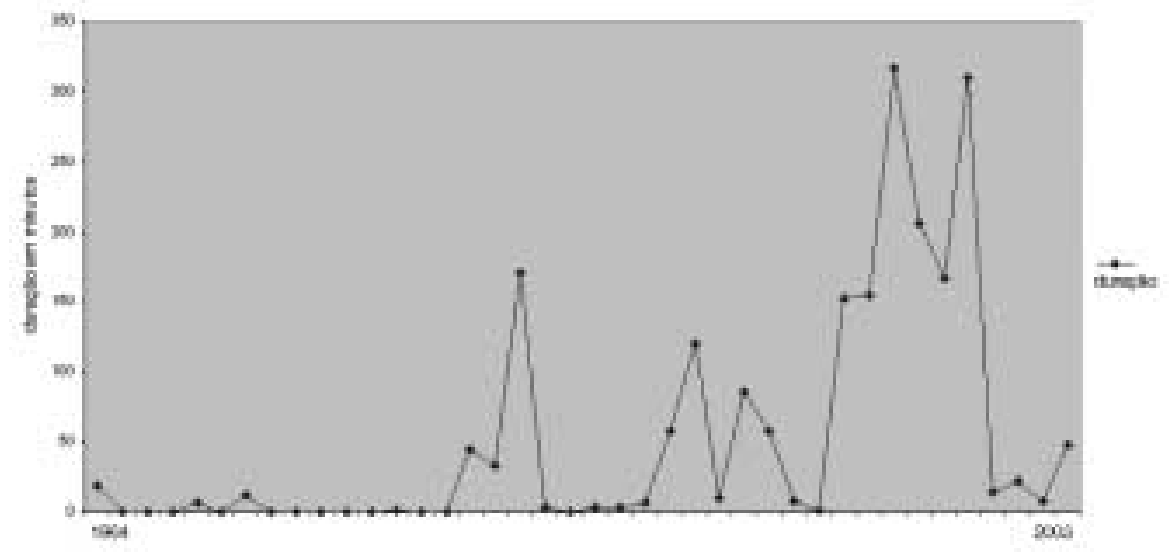

A segunda inflexão pode ser encontrada entre 1979 e 1981, quando, aos temas pitorescos - Dieu Noir de Race Brésil [Deus negro de raça Brasil]; Samba à Rio [Samba no Rio] e Le Brésil de Villa Lobos [O Brasil de Villa Lobos] -, se juntam temas socialmente engajados como os títulos Vivre avec 3 francs par jour (Viver com 3 francos por dia) e Je ne joue pas, je travaille [Eu não brinco não, eu trabalho]. Este último, com interesse particular, pois é a figura do Orfeu, herói romântico camusiano, que passa a mercantilizar sua arte. A terceira entre 1982 e 1993, cujo ponto culminante é o ano de 1987, é a em que a face cruenta das favelas aparece nos relatos sobre a guerra dos bandos de traficantes disputando o território. Através de títulos como Brésil: guerre des gangs [Brasil: guerra de gangues], Trafiquants de Drogue à Rio [Traficantes de Drogas no Rio], Favellas Brésil [Favelas Brasil], Guerre dans les favellas, Image du jour: émeuttes dans les favellas [Guerra nas favelas, Imagem do dia: agitação nas favelas] e Escadron de la mort Brésil [Esquadrão da morte, Brasil], a situação é comparada à de Chicago nos anos 1920 e o conjunto do problema qualificado como um problema de ghettos. Esta terceira inflexão conclui-se com dois títulos bastante significativos: Le pays de la delicatesse perdue (16/05/1990) [O país da delicadeza perdida] e Tristes tropiques (25/10/1990) [Tristes trópicos, alusão ao título do livro do antropólogo francês, Claude Lévi-Strauss], que dão a deixa para a fase seguinte: crianças abandonadas e favelas.

Entre 1994 e 1999, observa-se uma mudança de patamar na duração dos programas dedicados ao assunto. É nesse período que surge, na televisão francesa, o tema das crianças de rua. São desse período também as emissões "Je veux seulement être heureux" ["Eu quero simplesmente é ser feliz"], que aborda, segundo uma ótica católica, a questão das crianças abandonadas ou submetidas a algum tipo de vilolência, e o filme Orfeu, de Carlos Diegues.

O período 2000-2003 é marcado: pelo Fórum de Porto Alegre e a discussão sobre um modelo alternativo à globalização, que esse encontro traz para debate; e pela discussão a respeito de uma nova brutalidade e sobre a mudança de patamar do narcotráfico no Rio de Janeiro, apresentada no filme Cidade de Deus de Fernando Meirelles, repercutindo um lugar-comum que se consolidou ao longo dos anos 90 a respeito dos laços sociais no Rio de Janeiro: a falência ética e a dissolução dos pactos sociais. Nesse contexto, fecha-se um grande circulo mágico, em que a favela é apresentada completamente isolada do restante da cidade, como se fosse um território autônomo. Tudo isso tendo como referência simbólica os filmes de gângster, as sagas da máfia, o espetacular e a estética MTV (Bentes, 1999a). 


\section{À GUISA DE CONCLUSÃO}

Para uma compreensão abrangente da análise aqui apresentada, deve-se recuar à década de 1950. É nesta época que se forma uma espécie de imagem mitológica do Rio de Janeiro, assimilada na Europa, e especialmente na França: o Rio de Janeiro como capital cultural do Brasil, dos anos dourados do Copacabana Palace, do turismo internacional, das boates e dos cronistas sociais (Bentes, 1999b). É também nessa década que se nota um crescimento na curva de publicações no que se refere às favelas cariocas, quando os estudos passam a ser não mais sobre casos, mas sobre o conjunto das favelas do então Distrito Federal, conforme assinalado por Valladares (Valladares \& Medeiros, 2003). É no final da década de 1950 que o olhar das ciências sociais sobre as favelas se sistematiza:

acadêmicos norte-americanos que estiveram no Brasil na segunda metade dos anos 1950, preocupados com a integração e a organizaçẫo social dos migrantes de origem rural nas grandes cidades, introduziram a favela carioca no debate sobre a mudança social e a teoria do subdesenvolvimento. (Valladares \& Medeiros, 2003, p.11.)

Lembre-se também que, em 1949, num artigo intitulado "Research Needs in the Field of Modern Latin American Culture" (p.154), a favela carioca é citada como um lugar privilegiado para se estudar a chamada "criollo culture" (Tax, Wagley \& Gillin, 1949).

A transição dos anos 50 para os anos 60 assinala também a formação de uma narrativa e de uma imagem do Rio de Janeiro e, por derivação, do Brasil, iconizadas especialmente pela música e pelo cinema. As narrativas construíram uma visão romântica da pobreza, consolidada, especialmente na França, pela bossa-nova e pela letra de alguns sambas e por sambistas revalorizados (Moreno, 1982; Castro, 1990), mas muito particularmente, no caso francês, pelo filme de Marcel Camus de $1959,{ }^{4}$ Orphée Noir. A tônica era a de que o sambista, expressão artística da favela, do artista do povo, era portador de grande valor, mas não só não era reconhecido pela sociedade, como explorado por essa mesma sociedade: pobre, mas artista que não teve chance, ou que teve pouca chance, ou que tem apenas uma chance por ano, durante o carnaval. Um modelo com elementos românticos do artista não reconhecido, incompreendido pela sociedade que o cerca. Essa temática foi muito bem desenvolvida, por exemplo, nos trabalhos de Bentes sobre o cinema brasileiro (Bentes, 1999a, b), em que analisa a mudança no discurso a partir dos anos 1990 e o surgimento de novas formulações estéticas, ao comparar o cinema brasileiro atual com o Cinema Novo (anos 60), observando nesse último o fascínio pelos territórios dos subúrbios e favelas que levaram a uma romantização da miséria dos anos 1990. Vale a citação:

O Morro é apresentado no filme [de Camus] como lugar mítico e paradisíaco de uma pobreza desejável e glamourosa. Onde natureza e cultura são extensão uma da outra, onde a moradia popular, os "barracos", aparecem como "ocas" ou construção tosca, mas cheia de encantos, e onde o cartão postal típico do Rio de Janeiro, a Baía de Guanabara, é o quintal de casa. No filme, o trabalho é mostrado como prazer e libertação. Todas as mulheres rebolam e dançam enquanto carregam sua lata d'água na cabeça. O português, dono da venda, que é o único branco do morro, vende fiado em troca de beijos. 
Do ponto de vista imagético, será com esse ícone que a mídia francesa vai dialogar, ou seja, o que sempre foi uma realidade social de natureza dinâmica e criativa, passa a ser apresentada com as características de um objeto inorgânico, naturalizado.

Do ponto de vista da sociologia urbana, pode-se constatar que a estruturação interna da cidade do Rio de Janeiro é muito mais próxima à de um mosaico do que à de um gradiente decrescente de círculos concêntricos. A cidade do Rio de Janeiro se apresenta não como uma cidade segregada, partida, dual (Ventura, 1994; Ribeiro \& Telles, 2000), mas marcada tanto por dégradés quanto por dicotomias (Najar, 1998; Préteceille \& Valladares, 2000). Ela se apresenta como uma cerzidura, um mosaico, bem mais próximo ao que parece ter-se transformado a própria sociedade brasileira nas últimas décadas, muito embora alguns trabalhos recentes tenham indicado que, no interior deste, apesar da melhoria das condições gerais de vida ao longo dos anos 80, persistem lugares em condiçóes precárias onde predomina uma superposição de carências (Préteceille \& Valadares, 2000; Torres \& Marques, 2001).

A visão romântica, quase mítica, que se formou ao longo dos anos 1950 e início dos anos 60 a respeito da pobreza no Rio de Janeiro, e, por extensão, do Brasil, alimentou a visão dualista e polar que se encontra na quase totalidade das abordagens da televisão francesa. A construção, na França, da imagem do pobre e da pobreza, assim como das próprias camadas populares do Brasil, a partir dos anos 60 , se deu por meio da percepção da cidade do Rio de Janeiro, em especial de suas favelas, sendo os elementos constitutivos dessa imagem: uma sociedade dual e excludente, dividida em ricos (cidade) e pobres (favelas), sem classe média; cuja expressão artística única é o carnaval/batucada que invariavelmente conduz à lubricidade e à liberação de costumes.

Uma vez estabelecida a dualidade, as favelas passam a ser definidas, invariavelmente, a partir de alguns clichês tais como: "ces bidonvilles pauvres et surpleuplés" ["moradias precárias pobres e superpovoadas"], ou "des quartiers où se tassent millions des personnes qui survivrent entre prostitution et bandidisme" ["bairros onde se amontoam milhares de pessoas que sobrevivem entre a prostituição e o bandidismo"]. Ou então "où on trouve la violence à côté des belles plages", ["onde se encontra a violência ao lado de belas praias"] ou ainda as favelas são resumidas como "où il n'y a pas d'eau courrant, l'égout coule dans la rue et l'odeur est insoutenable" ["onde não existe água potável, o esgoto corre à céu aberto e o odor é insuportável"]. Todas são expressões que podem ser ouvidas à farta ao longo de diversos segmentos dos documentos que constituem o corpus da análise. Essas quase palavras de ordem e todo o texto vão constituir uma imagem, confirmando plenamente a hipótese desenvolvida em diversos trabalhos (Marchetti; 1997; Siracusa; 1998; Mills-Affif; 2002) de que é o texto escrito que forma as imagens. Essas imagens são as que aparecem sob a denominação de clichés na classificação por temas do conjunto de documentos examinados (Tabelas 6, 7 e 8). Esses clichés têm a particularidade de serem sempre uma seqüência de imagens mudas de curta duração, que traduzem os lugares-comuns da dualidade a respeito da cidade do Rio de Janeiro. Outra particularidade importante desses clichês é a de serem difundidos apenas nos jornais.

A única exceção constata-se nos anos mais recentes, em particular entre 2000 e 2003, quando as experiências do Fórum Social de Porto Alegre, os relatos de orçamento participativo e dos ensaios políticos e administrativos de participação democrática inauguram um novo texto associado às favelas, especialmente por conta da presença de deputados da esquerda francesa ao encontro. Mas identifica-se ainda facilmente a matriz interpretativa anterior, qual seja, o Brasil é visto, no que diz respeito aos problemas de urbanização e ocupação, através da favela carioca.
Alberto Najar é professor do Departamento de Ciências Sociais, Escola Nacional de Saúde Pública, Fundação Oswaldo Cruz. E-mail: najar@ensp. fiocruz.br

Sylvie Fégar é professora do Institut National de l'Audiovisuel, Inathèque de France.E-mail: sfegar@ina.fr

Artigo recebido para publicação em outubro de 2003. 
ANEXO

Quadro 1 - Corpus - Documentos audiovisuais selecionados e Utilizados nas Análises

\begin{tabular}{|c|c|c|c|c|c|c|c|}
\hline Base & Título do programa & Canal & $\begin{array}{c}\text { Data de } \\
\text { transmissão } \\
\text { corrigida }\end{array}$ & $\begin{array}{c}\text { Hora da } \\
\text { transmissão } \\
\text { corrigida }\end{array}$ & Duração & Temas & Tipologia \\
\hline IMAGO & Le Brésil & TF1 & $03 / 04 / 64$ & $20: 35: 00$ & $0: 19: 14$ & explicaçăo & magazine \\
\hline IMAGO & Les Coulisses d'un carnaval: RJ & TF1 & $23 / 02 / 68$ & 20:30:00 & 0:07:11 & condiçōes de vida & magazine \\
\hline IMAGO & Brésil: Escadron de la mort & TF1 & 29/05/70 & $21: 30: 00$ & $0: 12: 31$ & violência & reportagem \\
\hline IMAGO & Le Brésil & TF1 & $20 / 01 / 76$ & 13:20:00 & $0: 01: 30$ & clichê & jornal \\
\hline IMAGO & Le Brésil & TF1 & $21 / 01 / 76$ & $23: 13: 49$ & $0: 01: 20$ & clichê & jornal \\
\hline IMAGO & Un français du Brésil & TF1 & $30 / 07 / 79$ & 22:02:10 & 0:45:00 & alternativas & documentário \\
\hline IMAGO & Brésil Babylone est tombee & TF1 & $29 / 06 / 80$ & 10:32:00 & $0: 30: 00$ & condiçōes de vida & magazine \\
\hline IMAGO & La Bresilienne & FR2 & $12 / 07 / 80$ & 20:02:00 & 0:02:54 & violência & jornal \\
\hline IMAGO & $\begin{array}{l}\text { Dieu noir de race Brésil: Le } \\
\text { candomble un centre de resistance }\end{array}$ & TF1 & $11 / 01 / 81$ & 10:33:00 & $0: 30: 00$ & explicação & documentário \\
\hline IMAGO & Brésil & TF1 & $28 / 01 / 81$ & 20:05:00 & $0: 02: 20$ & clichê & jornal \\
\hline IMAGO & Je ne joue pas, je travaille & FR3 & $13 / 03 / 81$ & 20:34:00 & $0: 57: 43$ & crianças/jovens & magazine \\
\hline IMAGO & Le Brésil de Villa-Lobos & FR2 & 09/06/81 & $21: 21: 21$ & $0: 30: 00$ & explicaçăo & magazine \\
\hline IMAGO & Vivre avec 3 francs par jour & FR3 & 04/09/81 & 20:37:00 & $0: 48: 05$ & $\begin{array}{l}\text { comparaçāo } \\
\text { internacional }\end{array}$ & reportagem \\
\hline IMAGO & Samba a Rio & TF1 & $16 / 12 / 81$ & 23:30:00 & 0:02:06 & condiçōes de vida & jornal \\
\hline IMAGO & Carnaval Rio & TF1 & $03 / 03 / 82$ & 05 & 0:02:05 & clichê & jornal \\
\hline IMAGO & Violence Brésil & FR2 & $15 / 11 / 82$ & 2 & 0:03:36 & violência & jornal \\
\hline IMAGO & Adresse bidonville & TF1 & $02 / 11 / 83$ & $17: 40: 00$ & $0: 01: 30$ & crianças/jovens & jornal \\
\hline IMAGO & Plateau camara & TF1 & $06 / 11 / 83$ & 19:00:00 & $0: 20: 00$ & explicação & testemunho \\
\hline IMAGO & Carnaval de Rio & FR2 & $06 / 03 / 84$ & 20:26:00 & 0:01:34 & carnaval & jornal \\
\hline IMAGO & Carnaval de Rio et famine du nordeste & FR3 & 06/03/84 & 23:05:00 & 0:02:07 & explicação & jornal \\
\hline IMAGO & Mitterrand au Brésil & FR2 & $17 / 10 / 85$ & $12:$ & 0:01:16 & $\begin{array}{l}\text { cooperação } \\
\text { França/Brasil }\end{array}$ & jornal \\
\hline IMAGO & Mitterrand a Rio & TF1 & $17 / 10 / 85$ & 13:19:00 & 0:01:28 & $\begin{aligned} \text { coope } \\
\text { Françal }\end{aligned}$ & jornal \\
\hline IMAGO & Bilan du voyage de Mitterrand & FR2 & $20 / 10 / 85$ & 23:51:00 & 0:01:04 & $\begin{array}{l}\text { cooper } \\
\text { França/ }\end{array}$ & jornal \\
\hline IMAGO & Carnaval & TF1 & $02 / 02 / 86$ & $20: 3$ & $0: 01: 45$ & carnaval & jornal \\
\hline IMAGO & Brésil: Les favellas & FR3 & 07/07/86 & 23:09:00 & 0:02:34 & explicaçāo & jornal \\
\hline IMAGO & Les apprentis de l'esperance & TF1 & $26 / 12 / 86$ & 18:29:00 & 0:02:36 & $\begin{array}{l}\text { cooperaçăo } \\
\text { França/Brasil }\end{array}$ & jornal \\
\hline IMAGO & Oscar Niemayer & FR3 & $01 / 04 / 87$ & $23: 19: 14$ & $0: 48: 20$ & explicaçāo & documentário \\
\hline IMAGO & Brésil: Guerre des gangs & FR2 & $27 / 08 / 87$ & 13:05:00 & $0: 01: 12$ & violência & jornal \\
\hline IMAGO & Trafiquants drogue Rio & TF1 & $27 / 08 / 87$ & 13:14:20 & $0: 00: 53$ & violência & jornal \\
\hline IMAGO & Image du jour: emeutes dans les favelas & FR3 & $27 / 08 / 87$ & :01 & :00:56 & violência & jornal \\
\hline IMAGO & Brésil & FR2 & $27 /($ & 20:08:00 & 0:01:05 & violência & jornal \\
\hline IMAGO & Favellas Brésil & TF1 & $27 / 08 / 87$ & 20:13:16 & $0: 02: 35$ & violência & jornal \\
\hline IMAGO & Guerre dans les favellas & TF1 & $27 / 08 / 87$ & 23:27:00 & $0: 00: 53$ & violência & jornal \\
\hline IMAGO & Escadron de la mort Bré & TF1 & $13 / 10 / 87$ & 20:17:00 & 0:02:03 & violência & jornal \\
\hline IMAGO & Macumba & FR2 & $27 / 03 / 88$ & :32:00 & 0:03:02 & explicaçăo & jornal \\
\hline IMAGO & La mamma des & FR2 & $25 / 04 / 88$ & 22:24:35 & 0:06:00 & condiçōes de vida & magazine \\
\hline IMAGO & Cariocas, les & TF1 & $11 / 09 / 88$ & 23:51:20 & $0: 57: 35$ & explicaçāo & documentário \\
\hline IMAGO & L'or les filons de la fortune & FR3 & $14 / 10 / 88$ & 22:51:04 & $0: 51: 23$ & explicaçāo & documentário \\
\hline IMAGO & Violences a Rio & TF1 & $30 / 11 / 88$ & $13: 00: 07$ & 0:02:00 & violência & jornal \\
\hline IMAGO & Favelas a Rio & TF1 & 6/10/89 & :17:30 & 0:07:59 & violência & jornal \\
\hline IMAGO & Les favelles $\mathrm{du}$ & FR3 & 89 & & 0:02:10 & crianças/jovens & jornal \\
\hline IMAGO & Carnava & TF1 & 90 & re & 0:03:51 & carn & jornal \\
\hline IMAGO & Chico ou le pays de la delicatesse perdue & FR3 & $16 / 05 / 90$ & 20:39:00 & 1:04:17 & explicação & documentário \\
\hline IMAGO & Tristes tropiques & FR2 & $25 / 10 / 90$ & 20:40:00 & 0:17:09 & crianças/jovens & magazine \\
\hline IMAGO & Brésil la guerre des enfants & FR3 & 21/11/91 & 0:03:00 & 0:58:01 & crianças/jovens & reportagem \\
\hline IMAGO & Carnaval Rio & TF1 & & 1 & 0:04:50 & & jornal \\
\hline IMAGO & Favelas Rio & TF1 & & & 0:02:27 & condiçōe & jornal \\
\hline IMAGO & Massacre favelas 1 & FR3 & $31 / 08 / 93$ & $12: 45: 08$ & 0:01:30 & violência & jornal \\
\hline IMAGO & Massacre Rio/Brésil & FR2 & $31 / 08 / 93$ & 23:55:00 & $0: 00: 54$ & violência & jornal \\
\hline IMAGO & Une nuit a Rio & FR2 & $15 / 02 / 94$ & $0: 10: 56$ & 1:07:29 & carnaval & reportagem \\
\hline IMAGO & Rendez moi mon enfant & FR3 & $12 / 11 / 94$ & $20: 51: 25$ & $1: 24: 40$ & cinema & ficção \\
\hline DLTV & Les bals funk à Rio & Canal+ & $02 / 03 / 95$ & $0: 37: 26$ & 0:49:04 & hiphop & documentário \\
\hline IMAGO & Surf: Brésil, ecole da & FR3 & $04 / 04 / 95$ & $20: 39: 00$ & $0: 02: 38$ & alternativ & magazine \\
\hline DLTV & Sem cor & Canal+ & $25 / 05 / 95$ & $15: 43: 51$ & $0: 12: 26$ & crianças/jovens & ficção \\
\hline IMAGO & Police favela Rio & FR2 & $14 / 08 / 95$ & $20: 08: 12$ & 0:01:48 & violência & jornal \\
\hline IMAGO & Police favelas/Rio & FR2 & $14 / 08 / 95$ & 23:53:06 & 0:01:00 & violência & jornal \\
\hline DLTV & Les dérives de la vie politique & FR2 & $12 / 10 / 95$ & $0: 10: 45$ & $1: 28: 00$ & $\begin{array}{l}\text { comparaçāo } \\
\text { internacional }\end{array}$ & testemunho \\
\hline DLTV & Vite & M6 & $10 / 02 / 96$ & $0: 23$ & $0: 00: 18$ & hiphop & jornal \\
\hline DLTV & [Michael Ja & FR2 & $11 / 02 / 96$ & $20: 28: 20$ & 0:01:05 & biphop & jornal \\
\hline DLTV & Rio : la folie carnaval & M6 & $17 / 03 / 96$ & $20: 51: 14$ & 1:42:09 & carnaval & reportagem \\
\hline
\end{tabular}




\begin{tabular}{|c|c|c|c|c|c|c|c|}
\hline Base & Título do programa & Canal & $\begin{array}{c}\text { Data de } \\
\text { transmissão } \\
\text { corrigida }\end{array}$ & $\begin{array}{l}\text { Hora da } \\
\text { transmissão } \\
\text { corrigida }\end{array}$ & Duração & Temas & Tipologia \\
\hline DLTV & Là = Lá e cá & Canal+ & $20 / 03 / 96$ & $2: 35: 40$ & $0: 28: 31$ & cinema & ficção \\
\hline DLTV & Première : [Clip de Michael Jackson) & M6 & $21 / 03 / 96$ & 20:02:04 & $0: 00: 33$ & hiphop & jornal \\
\hline DLTV & Bourlinguer & TF1 & $01 / 05 / 96$ & $22: 44: 00$ & $0: 56: 29$ & $\begin{array}{l}\text { comparaçăo } \\
\text { internacional }\end{array}$ & reportagem \\
\hline DLTV & Vengeances & FR2 & $12 / 07 / 96$ & 20:57:09 & $1: 29: 19$ & cinema & ficção \\
\hline DLTV & Surfavela & Arte & $05 / 11 / 96$ & $21: 42: 31$ & $0: 37: 54$ & alternativas & documentário \\
\hline DLTV & [Post scriptum] : Tristes tropiques & FR2 & $23 / 01 / 97$ & $22: 45: 00$ & $0: 17: 08$ & crianças/jovens & reportagem \\
\hline DLTV & [Plateau invité : Michel Monpontet] & FR2 & $23 / 01 / 97$ & 23:00:00 & $0: 03: 38$ & crianças/jovens & reportagem \\
\hline IMAGO & Brésil/SAMBA & FR2 & $12 / 03 / 97$ & 13:11:00 & $0: 02: 19$ & condiçôes de vida & jornal \\
\hline DLTV & [Brésil favellas] & FR2 & $12 / 03 / 97$ & $20: 18: 38$ & $0: 02: 30$ & alternativas & jornal \\
\hline DLTV & [Zoom : favellas] & FR3 & $18 / 03 / 97$ & $23: 26: 08$ & $0: 02: 05$ & $\begin{array}{l}\text { cooperação } \\
\text { França/Brasil }\end{array}$ & jornal \\
\hline DLTV & La renaissance du cinéma brésilien & Arte & $30 / 05 / 97$ & 1:14:13 & $0: 26: 23$ & cinema & documentário \\
\hline DLTV & Brésil & FR2 & $28 / 08 / 97$ & $20: 55: 45$ & $1: 29: 12$ & explicação & documentário \\
\hline DLTV & $\begin{array}{l}\text { Jean Paul II persiste et signe = } \\
\text { Zwischen Politik und moral }\end{array}$ & Arte & $04 / 10 / 97$ & $20: 32: 27$ & $0: 01: 23$ & condiçōes de vida & jornal \\
\hline DLTV & La peau du foot & Arte & $27 / 11 / 97$ & $20: 51: 34$ & $0: 59: 00$ & futebol & documentário \\
\hline DLTV & (Brésil enfants de la rue] & TF1 & $29 / 12 / 97$ & $20: 19: 45$ & $0: 02: 57$ & violência & jornal \\
\hline DLTV & Villes brésiliennes & FR5 & $13 / 03 / 98$ & $10: 22: 19$ & $0: 26: 47$ & explicaçăo & reportagem \\
\hline DLTV & Les gamins aux pieds d'or & FR2 & $28 / 05 / 98$ & $22: 00: 57$ & $0: 22: 26$ & futebol & reportagem \\
\hline IMAGO & Les enfants des favellas & FR3 & $17 / 06 / 98$ & $12: 34: 00$ & 0:02:00 & crianças/jovens & jornal \\
\hline DLTV & Le chant du peuple & FR2 & $23 / 06 / 98$ & $23: 59: 23$ & $0: 25: 21$ & explicação & documentário \\
\hline DLTV & Le rythme du coeur & FR2 & $26 / 06 / 98$ & 0:07:55 & $0: 25: 55$ & explicação & documentário \\
\hline IMAGO & Football et favellas Brésil & FR3 & $12 / 07 / 98$ & $12: 43: 00$ & $0: 01: 55$ & futebol & jornal \\
\hline DLTV & Daniel & FR2 & $02 / 08 / 98$ & $18: 46: 04$ & $0: 01: 30$ & crianças/jovens & testemunho \\
\hline DLTV & Les fils du vent & FR2 & $11 / 09 / 98$ & $1: 05: 43$ & $1: 01: 25$ & crianças/jovens & documentário \\
\hline DLTV & $\begin{array}{l}\text { Brasilia: de l'utopie à la réalité = } \\
\text { Brasilia metropole vom reissbrett }\end{array}$ & Arte & 06/01/99 & $20: 13: 13$ & $0: 26: 53$ & explicação & documentário \\
\hline DLTV & $\begin{array}{l}\text { Je veux seulement être heureux = } \\
\text { Eu so quero é ser feliz }\end{array}$ & FR2 & $10 / 01 / 99$ & $10: 29: 17$ & $0: 28: 33$ & crianças/jovens & documentário \\
\hline DLTV & Galera & Arte & $12 / 01 / 99$ & $23: 06: 12$ & $1: 41: 11$ & crianças/jovens & documentário \\
\hline DLTV & Opus 1: Rio, le conservatoire de la samba & a M6 & $24 / 01 / 99$ & $6: 00: 40$ & $0: 54: 07$ & explicação & documentário \\
\hline DLTV & [Brésil Favela] & TF1 & $27 / 06 / 99$ & $20: 11: 16$ & $0: 02: 28$ & $\begin{array}{l}\text { cooperação } \\
\text { França/Brasil }\end{array}$ & jornal \\
\hline DLTV & [Brésil école cirque] & TF1 & $28 / 06 / 99$ & $20: 27: 50$ & 0:02:09 & crianças/jovens & jornal \\
\hline DLTV & [Urbanisme] & FR2 & $01 / 08 / 99$ & 12:05:01 & 0:38:00 & $\begin{array}{l}\text { comparaçāo } \\
\text { internacional }\end{array}$ & reportagem \\
\hline DLTV & [Orfeu] & TF1 & $26 / 10 / 99$ & $20: 35: 40$ & $0: 01: 31$ & cinema & jornal \\
\hline DLTV & Rio de Janeiro: Des flics dans la ville & FR2 & $06 / 12 / 99$ & 0:09:00 & $0: 55: 22$ & violência & documentário \\
\hline IMAGO & Brésil la musique des favelas & FR3 & $17 / 11 / 00$ & $22: 45: 00$ & $0: 11: 56$ & explicação & reportagem \\
\hline IMAGO & Off carte / favellas / tourisme & FR2 & $27 / 12 / 00$ & 13:34:00 & $0: 02: 15$ & alternativas & jornal \\
\hline DLTV & $\begin{array}{l}\text { [Porto Alegre: ville laboratoire de } \\
\text { la démocratie participative] }\end{array}$ & FR3 & $29 / 01 / 01$ & $19: 46: 35$ & $0: 02: 15$ & forum social & jornal \\
\hline DLTV & [Porto Alegre : modèle anti-Davos] & Canal+ & $04 / 02 / 01$ & $13: 13: 22$ & $0: 06: 25$ & fórum social & reportagem \\
\hline DLTV & Rio de Janeiro, les caméras de la favela & FR5 & $23 / 08 / 01$ & $9: 14: 17$ & $0: 13: 34$ & alternativas & documentário \\
\hline DLTV & [Forum Porto Alegre] & TF1 & $30 / 01 / 02$ & $20: 25: 38$ & $0: 01: 47$ & fórum social & jornal \\
\hline DLTV & [Enjeux Porto Alegre] & TF1 & $30 / 01 / 02$ & $20: 27: 37$ & $0: 01: 27$ & fórum social & jornal \\
\hline DLTV & [Cannes film brésilien] & FR3 & $19 / 05 / 02$ & $19: 50: 43$ & $0: 02: 10$ & cinema & jornal \\
\hline DLTV & [Misère au Brésil] & $\mathrm{TF} 1$ & $28 / 10 / 02$ & $20: 30: 03$ & 0:02:04 & condições de vida & jornal \\
\hline DLTV & [Les sommets de Davos et Porto Alegre] & Arte & $23 / 01 / 03$ & $19: 52: 50$ & $0: 01: 40$ & fórum social & jornal \\
\hline DLTV & [Film : La cité de Dieu] & FR3 & 09/03/03 & $19: 48: 58$ & $0: 02: 13$ & cinema & jornal \\
\hline DLTV & Nouvelle vague brésilienne & Arte & $15 / 03 / 03$ & $21: 57: 31$ & 0:09:00 & cinema & reportagem \\
\hline DLTV & [La cité de Dieu] & FR5 & $16 / 04 / 03$ & $15: 23: 25$ & $0: 04: 56$ & cinema & reportagem \\
\hline DLTV & Visitez les favelas à Rio & M6 & $06 / 05 / 03$ & $20: 58: 33$ & $0: 07: 43$ & condições de vida & reportagem \\
\hline DLTV & [Plateau : 2ème partie] & M6 & $06 / 05 / 03$ & $21: 06: 16$ & $0: 02: 31$ & condiçōes de vida & testemunho \\
\hline DLTV & [Le cinéma sud américain] & Arte & 09/05/03 & $19: 10: 25$ & $0: 19: 28$ & cinema & reportagem \\
\hline
\end{tabular}

Fonte: Inathèque de France. 
R I O D E J A N E I R O, A I M A G E M D A D I V I S Á O S O C I A L

\section{REFERÊNCIAS BIBLIOGRÁFICAS}

BENTES, I. "Central do Brasil: sertões e subúrbios no cinema brasileiro contemporâneo." Cinemas - Revista de Cinema e Outras Questôes Audiovisuais, n.15, p.85-96, 1999a. . "The sertão and the favela in contemporary Brazilian film." In: VIEIRA, J. L.; AVELLAR, J. C.; JENSEN, J.; XAVIER, I. Cinema Novo and beyond. Nova York: The Museum of Modern Art, 1999b. p.113-22.

BOLTANSKI, L. "Taxinomies populaires, taxinomies savantes: les objets de consommation et leur classement." Revue Française de Sociologie, v.XI, n.1, p.34-44, 1970.

BOURDIEU, P. "Éléments d'une théorie sociologique de la perception artistique." Revue Internationale des Sciences Sociales, v.XX, n. 4, p.640-64, 1968.

BOURDIEU, P. La distinction: critique sociale du jugement. Paris: Editions Minuit, 1979.

CASTRO, R. Chega de saudade: a história e as histórias da bossa nova. São Paulo: Companhia das Letras, 1990.

CHENU, A. "La déscriptibilité statistique des professions." Sociétés Contemporaines, n.26, p.109-36, 1997.

DREYER, E. Le Dépôt Légal: essai sur une garantie nécessaire au droit public à linformation. Paris: Librarie Générale de Droit et de Jurisprudence (L.G.D.J.), 2003.

FRANCE. ASSEMBLEE NATIONALE (1992). Loi n $92-546$ du 20 juin 1992, Loi relative au Dépôt Légal. NOR:MENX9100198L.

INATHEQQUE DE FRANCE - INA. Présentation de l'INA: Inathèque de France, 2003.

LARRIAGA, G. "Favellas de Rio de Janeiro." In: Panorama: le magazine de l'actualité télévisée. Paris: Institut National de l'Audiovisuel, 1968.

LEBOEUF, D., MEGY, C. "Le nouveau paradoxe de la programation: cibler et rassembler." Dossiers de l'Audiovisuel - La Documentation Française, Numéro Spécial 79, p.1-72, 1998.

MARCHETTI, D. Contribution à une sociologie des transformations du champ journalistique dans les années 80 et 90: à propos d' "événements sida"et du "scandale du sang". École des Hautes Études en Sciences Sociales, Paris, 707, 1997.

MILLS-AFFIF, E. Filmer les immigrés: les représentations audiovisuelles de l'immigration à la télévision française dans le documentaire et le reportage magazine (1960-1986). École Doctorale d'Histoire, Paris, 661, 2002.

MORENO, A. "Bossa Nova: Novo Brasil. The Significance of Bossa Nova as a Brazilian Popular Music." Latin American Research Review, v.17, n.2, p.129-41, 1982.

NAJAR, A. L. "Desigualdades de bem-estar social no município do Rio de Janeiro: um exemplo de aplicação da ferramenta SIG.” In: NAJAR, A. L.; MARQUES, E. Saúde e espaço: estudos metodológicos e técnicas de análise. Rio de Janeiro: Editora Fiocruz, 1998.

NAVEZ-BOUCHANINE, F. La fragmentation en question: des villes entre fragmentation spatiale et fragmentation sociale? Paris: L'Harmatan, 2002.

PRÉTECEILLE, E. Transformations de le ségrégation sociale: precarité, revenus, immigrés, jeunes en Ile-de-France. Paris: Cultures et Sociétés Urbaines - IRESCO (CNRS, Université de Paris 8): 88, 2001.

PRÉTECEILLE, E., VALADARES, L. "A desigualdade entre os pobres - favela, favelas". In: R. H. (Org.). Desigualdade e pobreza no Brasil. Rio de Janeiro: Ipea, 2000. p.459-85. 
PRÉTECEILLE, E., VALADARES, L. "Favela, favelas: unidade ou diversidade da favela carioca." In: RIBEIRO, L. C. de Q. O futuro das metrópoles: desigualdades e governabilidade. Rio de Janeiro: Revan/Fase, 2000. p.375-403.

RIBEIRO, L. C. de Q.; TELLES, E. "Rio de Janeiro: emerging dualization in a historically unequal city.” In: MARCUSE, P.; KEMPEN, R. Globalizing cities: a new spatial order? Londres: Blackwell, 2000. p.78-94.

SANTOS, P. F. Formação de cidades no Brasil colonial. Rio de Janeiro: Universidade Federal do Rio de Janeiro, 2001.

SFEZ, L. Dictionaire critique de la communication. Paris: Presse Universitaire de France, 1993.

SIRACUSA, J. Le corps des reporters et la forme des reportages: approche sociologique des actualités télévisées. Département de Sociologie. Paris: Paris 8: 768. 1998.

"Le montage de l'information télévisée." Actes de la Recherche en Sciences Sociales, n.131-2, p.92-106, 2000.

SOUCHON, M. "Des règles et des contraintes." Dossiers de l'Audiovisuel - La Documentation Française, Numéro Spécial 79, p. 5-6, 1998.

TAX, S., WAGLEY, C., GILLIN, J. "Research Needs in the Field of Modern Latin American Culture.” American Anthropologist, v.51, n.1, p.149-54, 1949.

TORRES, H.; MARQUES, E. C. "Reflexões sobre a hiperperiferia: novas e velhas faces da pobreza no entorno municipal.” Revista Brasileira de Estudos Urbanos e Regionais, n.4, p.49-70, 2001.

VALLADARES, L. de P. "Favelas, mondialisation et fragmentation." In: NAVEZ-BOUCHANINE, F. La fragmentation en question: des villes entre fragmentation spatiale et fragmentation sociale? Paris: L'Harmatan, 2002a. p.209-21.

Le langage de la coopération internationale. Peace Corps et ONGs dans les favelas à Rio de Janeiro. In: CEFAII, D.; JOSEPH, I. L’héritage du pragmatisme: conflits d'urbanité et épreuves de civisme. Aube: Éditions de l'Aube, 2002b. p.175-91.

VALLADARES, L. de P.; MEDEIROS, L. Pensando as favelas do Rio de Janeiro, 19062000: uma bibliografia analítica. Rio de Janeiro: Relume Dumará/ Faperj/Urbandata, 2003.

VENTURA, Z. Cidade partida. São Paulo: Companhia das Letras, 1994.

VILAN, T. Image des favelas dans des ouvrages grand public de langue française: pensée urbanistique et habitat non-réglementé. Institut d'Urbanisme de Paris. Val-de-Marne, Paris: Université Paris XII: 59. 1993.

A B S T R A C T The objective of this article is to analyze the characteristics of French television broadcasts that approach the theme of favelas (slums) in the city of Rio de Janeiro, Brazil, in TV programs aired from April 1964 to May 2003. The purpose was not to analyze the images per se, but to identify the characteristics of audiovisuals dealing with the issue of favelas, in terms of the programs, the themes covered, duration, and the time of the day in which the programs were broadcasted. Two different data basis were used from the Inathèque de France, namely the Dépôt Legal and the Archives INA TV (IMAGO). Analysis of the results suggests a sharp social division in Rio de Janeiro through the image of the favelas as reported on French TV under the genre of news broadcasts and magazines, mostly aired from 11:31 to 13:30 PM), on channels TF1, FR2, and FR3 (70\% of broadcasts). Longer genres such as documentaries, tending to produce a more in-depth analysis and sometimes proposing a 
R I O D E J A N E I R O, A I M A G E M D A D I V I S Ã O S O C I A L

broader explanation of the phenomenon were generally only aired after 10:30 PM, both on the FR2, FR3, Canal+ and Arte channels. The conclusion highlights that Rio de Janeiro's socio-spatial structure is more complex than that captured by such a dualistic model. The city's socio-spatial nuances are lacking in the audiovisual programs broadcasted by French TV, and the approach to the favela issue is thus based on a mythical-romantic view as portrayed in Black Orpheus, by Marcel Camus.

K E Y W O R D S Rio de Janeiro; social division image; slums; Inathèque de France; television broadcasts. 